\title{
Intelligent Extension of Legal Logic: Challenge and Direction
}

\author{
Zhi Zhang \\ College of Humanities, China University of Political Science and Law, Beijing, China \\ Email: hainingshixisheng@163.com
}

How to cite this paper: Zhang, Z. (2020) Intelligent Extension of Legal Logic: Challenge and Direction. Beijing Law Review, 11, 759-769.

https://doi.org/10.4236/blr.2020.113046

Received: July 17, 2020

Accepted: September 20, 2020

Published: September 23, 2020

Copyright ( 2020 by author(s) and Scientific Research Publishing Inc. This work is licensed under the Creative Commons Attribution International License (CC BY 4.0).

http://creativecommons.org/licenses/by/4.0/

\begin{abstract}
Under the stimulation of artificial intelligence, legal logic has a tendency of intelligent expansion. The tendency is mainly manifested in three aspects; the first is the automation of the matching of legal norms; the second is the calculus of facts to be proved; and the third is the modeling of legal decisions. In the process of intelligent expansion of legal logic, the challenges it faces are as follows: the challenge of creativity in legal norms, the challenge of complexity of facts to be proved, and the challenge of balance of legal value. In the face of these challenges, the intelligent expansion of legal logic should adhere to the direction of scientific development. Legal logic must adhere to the practice of judicial decision, pay attention to non-monotonic logic and reasonable reasoning, and deepen and expand the cause-and-effect relationship.
\end{abstract}

\section{Keywords}

Legal Logic, Intelligence Expansion, Artificial Intelligence, Legal Norms, Facts to Be Proved

\section{Introduction}

How to use logic to study legal issues is the core of legal logic research. The initial research approach is to use the traditional logic theory to analyze legal cases, which is established on the traditional deductive logic and inductive logic. Since traditional logic theory focuses on formal research methods, it is unable to carry out effective research on the complicated practical legal issues. Therefore, the legal logic needs a more universal definition and a clearer research scope in order to achieve its practical turning goal.

Legal logic is a discipline concerned with legal thinking and its laws, its research object and system should proceed from the field of legal thinking and its basic problems. The research objects of legal logic include factual reasoning, le- 
gal reasoning, judgmental reasoning and the laws, rules and methods of argumentation. The disciplinary system established based on these contents is completely different from the formal research framework of traditional logic on legal cases (Wang, 2016). From the broad disciplinary system constructed, it can be found that the scope of application of legal logic is very wide. The research field of legal logic is not confined to a single legal regulation, nor is it imprisoned in a certain case. Rather, it runs through the beginning and the end of the structure of legal norms and the process of law application.

From the perspective of epistemology, legal logic belongs to applied logic, which is the application of logical knowledge in legal phenomena. At the same time, legal logic is one of legal methodology, which is one of the methods to study legal phenomena. Therefore, it is entirely possible to look at the field of application of legal logic from two aspects, and answer the question of "how does logic apply to the field of law". On the one hand, from the perspective of legal norms themselves, legal logic studies the structural theory of legal norms. On the other hand, in terms of the application of logical methods, legal logic also studies the model theory of legal argumentation (Lei, 2017). Legal logic focuses not only on the logical construction of legal norms, but also on the judicial practice of logical methods.

With the development of society and the constant updating of law, the study of legal logic must also face the ever-changing social changes. Both traditional logic methods and modern logic methods, they are gradually integrated with other disciplines, complementing and innovating in the cross-development. In particular, the promotion of artificial intelligence has opened up a new approach for the study of legal logic. Some scholars advocate broadening the research path of legal logic through new emerging interdisciplinary subjects, such as pragmatics and cognitive science, to shape a new type of legal logic to expand the research field of legal logic, to improve the rationality of legal thinking by integrating legal methods (Lv \& Jiao, 2019).

A further claim is to revolutionize traditional legal logic, researchers should construct a new legal logic system under the new era background; new legal logic needs to incorporate more logic tools, which can meet the needs of future development (Huang \& Li, 2019). The expansion of legal logic requires the creation of a new type legal logic; it should be oriented towards the possible life of humanity in the modern rule of law. The emergence of artificial intelligence has pointed out a new direction for the expansion of legal logic; it also provides new ideas for the transformation of the legal thinking rules of natural language into the legal logic rules of artificial language (Chen, 2019).

Intelligent development is the need of the development of legal logic itself, not only from the fusion of emerging disciplines and logical theory, but also from the realistic requirement of social legal progress. Since legal logic takes classical deductive logic and modern mathematical logic as its research tools, symbolization, formalization and systematic deduction are the important means for him to 
explore legal thinking. Therefore, there are theoretical basis and instrumental conditions for expansion of intelligence. The intelligent expansion of legal logic can be summed up as follows: First, the automation of legal norm matching, which should be manifested as automatic search and active matching of legal keywords. Second, the calculus of legal fact finding, it is prominently manifested in the digitization of evidence, the combination of evidence is completed by using mathematical model. Third, modeling legal decisions, through the logical model to construct the legal reasoning structures, make the legal decision show the process of intelligent deduction.

\section{The Intelligence Expansion of Legal Logic}

\subsection{Automatic Matching of Legal Norms}

The matching of legal norms is the basis of discovery of law, its automated turn provides convenient conditions for discovery of law. The superficial meaning of discovery of law is to seek for legal norms, which can be simply understood as the process of discovering laws and regulations. If discovery of law is seen as a mechanized process, which is the matching process of "keywords": find "keywords" identical or similar, associate the laws that contain these keywords, and think them are the same or similar provisions for specific events or behaviors.

The big data function of artificial intelligence meets the mechanized demands of discovery of law. First, the storage function of big data, the legal regulations are stored in a legal database, which has a large capacity to meet the storage requirements of various types of legal norms. Second, the automated function of reading and matching big data, it will save the judicial personnel time and effort to search for and read legal norms. Third, the association function of big data, not only is it easier for judicial personnel to discover the target legal norms, but also for them to discover the relevant legal norms, including upper law and lower law, procedural law and substantive law, etc. It can be said that an automated process based on matching legal norms, AI provides a quick and effective tool for discovery of law, it provides an integrated function of storing, retrieving, reading, matching for legal norms.

\subsection{The Calculus of Facts to Be Proved}

The core concern of legal logic includes legal reasoning, among them, factual reasoning is to solve factual problems in legal reasoning. Legal facts are stipulated by law and can cause the occurrence, alteration and elimination of legal relationships. One of the effects of discovery of law is the discovery of legal facts. The basic requirement of legal reasoning for facts is to judge, whether the disputed facts between the parties are legal facts, or whether the facts accused by the prosecution are legal facts.

How to resolve disputed facts in the law? The root of the resolution of the disputed facts is evidence. Only claims that can be proved by evidence can be legally recognized as facts, claims that cannot be proved by evidence cannot be 
called "facts". The law provides a due process for evidence to prove the facts, that is, litigation process. The plaintiff in civil litigation who bears the burden of proof shall submit evidence according to law, and fulfill the persuasive responsibility by the evidence presented, the defendant may present his own evidence to refute the plaintiff's claim. There must be sufficient legal evidence for the prosecution of criminal proceedings undertaking allegations, to prove that the defendant committed the alleged crime, the criminal defendant and his lawyer can propose to defend the prosecution's evidence.

But the facts exist in the past tense. In actual litigation, there is no guarantee that the evidence in it can discover and determine the facts completely, accurately and absolutely. On the one hand, the evidence cannot always be completely presented in court, and sometimes the key evidence will be missing in reality. In addition, litigation evidence is also subject to illegal evidence exclusion rules, evidence that is illegal and affects the determination of facts will be excluded in the lawsuit. On the other hand, people's understanding of past events is not only limited by their own cognitive ability, but also by objective space-time conditions. Legal proceedings have a time limit for trial, that is, the duration of action is limited, it is impossible to prolong the proceedings indefinitely on the facts of the case. It can be said that the legal proceedings in reality cannot guarantee that the legal facts are objective facts. In view of this, all methods that help to find facts to be proved will be favored by legal litigation research.

Why artificial intelligence can promote the intelligence of legal logic in the field of fact? The main reason is that it has three elements: first, algorithm, second, computing power, and third, the development of big data (Li, 2019). These elements are concentrated in "normative reasoning based on evidence", that is, if the best available evidence shows the choosing $\mathrm{X}$ is most likely to produce the desired result, then $\mathrm{X}$ should be chosen (Callow, Frumkin, \& Kerr, 2018). In other words, if the legal evidence possesses the functions of deduction and calculation, then the facts to be proved can be deduced by means of intelligent calculus. The mechanism of artificial intelligence for calculus reasoning mainly focuses on two aspects. One is deductive reasoning through causal associations between events, reasoning from sufficient and necessary relationships between premises and conclusions. The mechanism is to correlate events from the perspective of logical relationship, that is, causal correlation. The other is mathematical reasoning, which associates evidence with facts through probability models. The function of probability models is to obtain probability data about the occurrence of a particular event. The mechanism is to correlate events from the perspective of mathematical calculation, that is, data correlation.

\subsection{Modeling Legal Decisions}

Modeling legal decisions means that the use of law to adjudicate specific cases can follow a fixed pattern of legal decisions. Modeling legal decisions presuppose three conditions. The first condition is that the judge of law must be a rational 
person, he must maintain a sober understanding, able to identify the pros and cons, find the key points, and without personal calculation of gains and losses. At the same time, he also has the ability to predict the maximum expected value. The second condition is that specific cases can be typed. Legal adjudicators are able to categorize a wide variety of cases, remove too much detail from the cases, and preserve the body of them. The adjudicators should not only know how to type the facts to be proved in these cases, but also know how to type the applicable law of these cases. The third condition is that the adjudicator can make "the same legal decision for the same cases", they also can make "the different legal decision for the different cases". The third condition implies a premise that there is a distinction between "the same cases" and "the different cases", and that the adjudicator, as a rational person, can distinguish them.

The most typical form of "modeling legal decision" is the syllogism of judicial decision. The syllogism of judicial decision has such structure: the main premise of judicial decision, the minor premise of judicial decision, and the conclusion of judicial decision. The main premise of judicial decision is about the legal norms applicable to judicial decisions; discovery of law is the premise of the application of legal norms. The minor premise is about the facts to be proved by judicial decision, and factual reasoning solves the factual problem in legal reasoning. According to the logical reasoning rules of syllogism, the conclusion is the result that must be deduced from the premises through the combination of legal norms and the facts to be proved. The syllogism of judicial decision combines the legal norm and the facts to be proved in the structure; the joint point is the legal fact in the legal norm. The connection between legal facts and facts to be proved is the basis of application of syllogism in judicial decision.

\section{The Challenge of Intelligent Expansion of Legal Logic}

\subsection{The Challenge of Creativity in Legal Norms}

"Interpretation" and "Continuation" of legal norms, they are the primary challenge for the intelligent development of legal logic. The application of legal norms is not a simple keyword matching, but a creative logical thinking activity. There are "gaps" between legal norms and social phenomena, since legal norms cannot cover all social phenomena, which will appear loopholes. There may be certain social phenomena that are not restricted by legal regulations. Facing the ever-changing social changes, legal norms have "lag". How to deal with the problems in society through "interpretation" and "continuation" of legal norms, which is also a practical problem faced by the intelligent expansion of legal logic.

"Gaps" between legal norms and social phenomena, it means that legal norms and social phenomena are not one-to-one correspondence. For example, whether imported tomatoes are bound by the laws of imported vegetables or imported fruits? As another example, if "motor vehicles are not allowed to enter" posted at the door, can children's cars with batteries enter? Whether specific things and behaviors can be incorporated into specific legal norms, there are many disputes 
in the real world. Because the general objects targeted by the legal norms and the special objects in social life are incompatible, as a result, there exists "gaps" between legal norms and social phenomena. To bridge these "gaps" requires life experience and common sense in society, these are things that AI doesn't have.

Faced with real social problems and emerging social phenomena, legal regulations also have "holes". The legal loopholes are mainly manifested in the fact that the law does not provide direct regulations, and in the face of specific social issues, there are no express legal provisions. Sometimes the legal norms will stipulate certain social issues in general, but they cannot answer specific case questions. For example, if somebody know that a certain product is a counterfeit product, and purchase with the purpose of "counterfeiting", can he be called consumers. Should he be protected by the Consumer Rights Protection Law? Faced with social phenomena and practical problems, legal norms cannot be stipulated in full, resulting in laws that cannot regulate all specific issue in society.

"Lagging nature" of legal norms means that the law depends on the cognitive level of the legislator, limited by the limitations of the time when the legislation was made. The promulgation of legal norms is a long-term process. It takes time from the emergence of new social phenomena to brewing into the scope of adjustment to legal norms. It must be clear that society has always been in a dynamic movement, and the formulation, promulgation of laws and regulations must be subject to the limitations of the times and social cognition. For example, in an era when the Internet did not appear, it was impossible to formulate laws that regulate the development of the Internet. Only after the emergence of the Internet, a series of social life phenomena and related problems on the Internet will appear. Therefore, the legal regulations on the Internet must be formulated after the Internet.

The challenge of intelligent expansion of legal logic, means that the intelligence of legal logic must be able to handle the "gaps" between legal norms and reality, and "loopholes" and "lags" in legal regulations. Can artificial intelligence perform the functions of "interpretation" and "continuation" of legal norms? The interpretation of legal norms is a very complex task, it includes literal interpretations, interrelated logical interpretations, and systematic interpretations involving context, as well as historical interpretations that relate to specific legislative periods, etc. As far as the literal interpretation is concerned, it includes not only the interpretation of the surface meaning, but also the restrictive interpretation and the expanded interpretation. The "continuation" of legal norms is the active creation activity of judges aiming at individual cases. Under the guidance of the objective legal principle, judges fully mobilize their knowledge, morality and other subjective factors to solve objective practical problems. It is the unity of individual subjective initiative and objective judicial activities. It can be seen that the comprehensive knowledge and creative ability of the interpreter are tested by "interpretation" and "continuation" of legal norms, rather than looking 
at a single logical capability of artificial intelligence.

\subsection{The Challenge of Complexity of Facts to Be Proved}

The "assignment" of evidence evaluation and the "reliability" of the calculation of the facts to be proved, they are the most formidable challenge that the intelligent development of legal logic faces. To arrive at the facts to be proved by intelligent calculus, accurate "assessment" and precise "assignment" of evidence are necessary. However, whether the evidence can be accurately "assessed" determines the precise "assignment" of its proving power, this is a controversial issue. The proving power of evidence refers to the strength of the evidence to prove the facts. In empirical evaluation, the strength of a piece of evidence pointing to a specific fact is usually a fuzzy value; it is difficult to determine it using precise numerical values. To evaluate the power of certain evidence, often need to consider many variables, they are ambiguous and unpredictable. For example, when a witness give testimony in court, he sweats, his hands shake unconsciously, he blinks from time to time, and he hesitates to speak. What is the strength of the witness's testimony? Will its strength be compromised by the bad conduct of the witness? The variables of evidence are too complex and vague to be given precise values.

What type of calculation model should be used to calculate the facts, which is one of the main issues surrounding whether intelligent legal logic can accurately calculate the facts to be proved. The mainstream view is to use Bayesian models to combine evidence, through mathematical logic calculation, to establish the percentage of the possibility of a certain claim. Bayesian model is a conditional probability model; it is a probability calculus model that converts prior probability into posterior probability by likelihood ratio. For a fact to be proved, the realization of the adjudicators need to form a probability value about its being true, namely the prior probability. They also need the ratio, which between the probability of finding evidence if the claim is true and the probability of finding evidence if the claim is not true, namely the likelihood ratio. Then the product of prior probability and likelihood ratio can be obtained as follows: the probability value of the fact to be proved under the condition of finding evidence, that's the posterior probability. Bayesian model is essentially a mathematical model based on probability axioms, which is derived from the product law and the negative law after conversion. Can the probability of the "facts to be proved" be deduced by Bayesian model? Does the prior probability necessarily preexist in people's beliefs? Are people's estimates of likelihood ratios accurate? Is the posterior probability reliable or valid? These questions remain controversial. Moreover, even if Bayesian models can be applied to the calculus of facts to be proved, their complexity can be daunting. There are also indescribable conceptual connotations that make people who do not understand the Bayesian model calculations confused and doubtful.

Whether the results obtained by the mathematical model calculation are suffi- 
cient to ensure the reliability of the "facts to be proved", this question actually requires people to answer: Can the results obtained from the mathematical model calculation be verified or falsified? "Facts to be proved" are an integral part of "case facts", as a result of legal evidence, they are not repeatable. Unlike experimental science, the facts of a case can only be obtained by means of reasoning and proof, judges, prosecutors, parties and witnesses are all in court together; they prove the facts of a case by presenting evidence, fulfill persuasion responsibilities and make a decision based on the burden of proof in the law. The legal evidence is different from the experimental materials, and the facts of the case are not the data of the experimental results. The confirmation of the facts of the case can only be reflected in the process of judicial certification. Critical rationalist Karl Popper believes that the essence of science is to be falsified, and the reliability of science is that it can be verified. To what extent does the result of mathematical model calculation conform to "objectively occurring facts", relying on the mathematical model alone cannot answer its reliability. Lack of confirmation and falsification, they all bring unreliable feeling to the results of mathematical calculations, which in turn affect the "acceptability" of the decision.

The admissibility of the decision refers to whether the process and result of the judicial decision can be accepted by parties and the public. This acceptance is not based on coercive force, but comes from their inner belief in the legitimacy of the judicial decision process and the accuracy of the results. Substituting the mathematical model calculation process for the trial proof process will obscure the procedural rationality and substantive rationality of the judicial trial. For example, the Bayesian model, the posterior probability is mainly obtained by the continuous product of the prior probability and the likelihood ratio. The mathematical model calculation process is completely different from the litigation process that relies on due process, which has neither visualization nor transparency. Due to the lack of social empirical understanding and reliable explanation, the result value calculated by the mathematical model is difficult to get public approval. It can be seen that what the pure mathematical logic calculation or intelligent calculation brings to the facts of the case is not "acceptability" but "unacceptability".

\subsection{The Challenge of Balance of Legal Value}

Law is the law of society, which must contain the value of society. The challenge of weighting the legal value refers to whether the intelligence of legal logic can weigh the legal value in individual cases and consider the whole case comprehensively. Legal value refers to a situation where the law is the object and the person is the subject, whether the subject is satisfied from the object's attributes and fulfills his own survival needs. The legal value will not be realized on its own initiative, but needs to be realized in the operation of the law; it depends on the application of the law. The legal value is plural, which mainly includes freedom, 
equality, human rights, justice, order, etc. They are not always harmonious and orderly, they also conflict in individual cases, for example, how to effectively deal with the conflict between personal freedom and social order. The problem faced by the intellect intelligence of legal logic is whether and how it can discover and screen these legal values in individual cases. Under the conditions of taking into account both legality and reasonableness, let the multiple values of law be balanced in an orderly way.

Challenges faced by the intelligent expansion of legal logic, the underlying reason lies in the fact that the functions of artificial intelligence cannot meet the ever-changing needs of human thinking and social life. If the law follows the requirements of pure logic, then the design of artificial intelligence would become clear: the design of reasoning thinking in the practice of law would be strictly in accordance with "deduction, induction, abduction and analogy". But pure logic is difficult to cover all aspects of social life, also difficult to apply to the field of experience of the case. At a time, when logic algorithms have no rules to follow, it will be a very long process for artificial intelligence to solve the logic and empirical reasoning problems (Yang, 2019).

\section{The Direction of Intelligent Expansion of Legal Logic}

\subsection{Turning to Practice of Judicial Decisions}

The vitality of the law is that it can be applied, and it is fully applied. The famous justice Holmes once said, "The life of law lies not in logic but in experience". From Holmes' appreciation of life experience, we can know that he is a representative of empirical law, and he advocates practical reason. It must be admitted that if logic is simply understood as formal deduction or syllogism, then it really cannot dominate the law. However, legal logic cannot be confined to a closed system of formal deduction. Instead, the logic needs to be extended to a creative thinking about law. Logic should run through the operation of law as well as experience. Laws do not work effectively if against logic or without experience. Legal logic should face the practical problems in judicial practice and pay attention to the creativity in judicial decisions. Only in this way can it be expanded intelligently and solve the practical problems in judicature. Therefore, the intelligent expansion of legal logic should face the practice of judicial decision in the future.

\subsection{Focus on Non-Monotonic Logic and Reasonable Reasoning}

Non-monotonic logic is different form monotonic logic; the validity of monotonic logic focuses on semantic truth, the validity of non-monotonic logic emphasizes the rationality of the actual situation. If monotonic logic satisfy the requirements that premise is true, it will reach a true conclusion, but for Nonmonotonic logic, it needs to satisfy a reasonable interpretation of reality. The goal of non-monotonic logic is to achieve reasonable reasoning, this rationality emphasizes that the premises and conclusions of reasoning should be common 
sense, and they can explain the reality reasonably. To put it simply, non-monotonic logic does not study reasoning for its own sake, but for the sake of reality. In fact, legal reasoning is a kind of creative reasoning, which pays more attention to reasonable reasoning. Non-monotonic logic is more consistent with the realistic content and practical objective of legal logic.

\subsection{The Deepening of Causal Association}

Causality is the science of "why", exploring causality helps humans understand their own cognitive processes better, mastering causal associations and constructing causal reasoning can make artificial intelligence more powerful. First, construct causal association based on data association. In the context of the era of big data, the most typical form of causal association is data association. The digitization of object objects lays the foundation for the analysis of their association, and the most direct purpose of statistical science is to discover the objective laws hidden behind the data. Statistical evidence is increasingly used as forensic scientific evidence, data technology has become an essential tool for expert witnesses; they grab relevant information by analysis of data. Second, establish a solid conditional relationship on the basis of empirical observation, in order to ensure that sufficiency of the conditions has a sufficient empirical basis. The solid causal relationship is not in the sequence of isolated events, but in a conditional relationship network. The sufficient condition between cause and effect not only possesses a logical relationship, but also gains support from human experience. In short, strengthening the research on logical intelligence of causality will help to realize the transition from weak AI to strong AI, in order to further promote the intelligent expansion of legal logic.

\section{Conclusion}

Legal logic as a research tool for the unification of theory and practice of law, it has the advantages of parallel development and mutual integration with "artificial intelligence and law". Legal logic, however, is not a purely technical study of deductive reason; it also requires attention to the social realities and other important values of the law, such as moral requirements, policy orientation and so on. Legal logic is not a mechanical legal application or one-way legal method, which requires dimensional thinking and weighing. The application of legal logic must meet the needs of judicial practice, such as the rationality of legal regulations, the reliability of facts, the acceptability of legal decisions, and so on. In short, the subject of legal logic is human, not artificial intelligence.

The development of artificial intelligence will be the main driving force for the development of logic; the difficulty with artificial intelligence is not to simulate the kinds of inevitable reasoning that the human brain does, but the initiative and creative thinking, which can reflect the most intelligent characteristics of human (Chen, 2016). "Legal logic is concerned with the analysis, evaluation or construction of legal reasoning or legal argumentation, which is premise of the 
analysis of judicial cases and legislative effects. So in a sense, the level of legal logic research determines the research and development level of 'artificial intelligence and law"' (Zhang \& Hou, 2019). It can be seen that research level of legal logic restricts and determines the research level of "artificial intelligence and law". The intelligent expansion represents an important development direction of legal logic research, formal deduction and necessity reasoning in the field of law; they will be more accountable to artificial intelligence; legal logic is more focused on the regular exploration and creation of human in legal thinking.

\section{Conflicts of Interest}

The author declares no conflicts of interest regarding the publication of this paper.

\section{References}

Callow, R., Frumkin, M., \& Kerr, I. (2018). Dialogue between AI and the Law (pp. 119-120, Chen Jidong, Dong Huimin, Hang Yingying, Translation). Shanghai: Shanghai People's Publishing House.

Chen, B. (2016). What Is Logic (p. 301)? Beijing: Peking University Press.

Chen, J. Z. (2019). Research on Expansion of Legal Logic (Artificial Intelligence and Law). Legal Method, 2, 94-95.

Huang, Z. M., \& Li, G. G. (2019). Outline of Constructing New Legal Logic. Journal of Shanghai College of Political Science and Law, 1, 39-43.

Lei, L. (2017). What Does Legal Logic Study. Tsinghua University Law Journal, 4, 188-208.

Li, Z. L. (2019). Artificial Intelligence Entered the Legal Field in an All-Round Way? Do Three Things First. In Huayu Yuandian Legal Artificial Intelligence Research Institute (ed.), A Legal Professional's Guide to the Artificial Intelligence (p. 347). Beijing: Law Press.

Lv, Y. Z., \& Jiao, B. Q. (2019). The Extension Research of Legal Logic: The Background of Emerging Interdisciplinary Subjects. Journal of Shanghai College of Political Science and Law, 1, 27-38.

Wang, H. (2016). The Discipline of Legal Logic (2nd ed.). Beijing: China University of Political Science and Law Press.

Yang, Y. C. (2019). AI Law: Building a New Order for the Future of Mankind (pp. 43-46). Beijing: Law Press.

Zhang, B. Q., \& Hou, Y. L. (2019). Smart Courts and Procurators: Big Legal Data Enables the Upgrading of the Judicial Industry. In Huayu Yuandian Legal Artificial Intelligence Research Institute (ed.), A Legal Professional's Guide to the Artificial Intelligence (p. 154). Beijing: Law Press. 